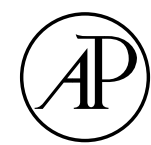

ACADEMIC PRESS

\title{
Accuracy of cosmogenic ages for moraines
}

\author{
Jaakko Putkonen* and Terry Swanson \\ Quaternary Research Center and Department of Earth and Space Sciences, University of Washington, MS 351310, Seattle, WA 98195, USA
}

Received 16 January 2002

\begin{abstract}
Analyses of all published cosmogenic exposure ages for moraine boulders show an average age range of $38 \%$ between the oldest and youngest boulders from each moraine. This range conflicts with the common assumption that ages of surface boulders are the same as the age of the landform. The wide spread in boulder ages is caused by erosion of the moraine surface and consequent exhumation of fresh boulders. A diffusion model of surface degradation explains the age range and shows that a randomly sampled small set of boulders $(n=$ 3-7) will always yield a lower age limit for the moraine. The model indicates that for identical dating accuracy, six to seven boulders are needed from old and tall moraines (40,000-100,000 yr, 50-100 m initial height) but only one to four boulders from small moraines (20,000-100,000 $\mathrm{yr}, 10-20 \mathrm{~m})$. By following these guidelines the oldest obtained boulder age will be $\geq 90 \%$ of the moraine age $(95 \%$ probability). This result is only weakly sensitive to a broad range of soil erosion rates. Our analysis of published boulder ages indicates that $<3 \%$ of all moraine boulders have prior exposure, and $85 \%$ of these boulders predate the dated moraine.

(C) 2003 Elsevier Science (USA). All rights reserved.
\end{abstract}

Keywords: Cosmogenic exposure-age dating; Moraine; Boulder; Dating; Erosion

\section{Introduction}

Geological processes affecting moraines complicate the interpretation of moraine ages derived through cosmogenic exposure dating of boulders found on moraine crests. Typically, small numbers of boulders are analyzed $(n=5)$, and these show a large range of ages. Can an age for the moraine be found from these boulder ages, and what is its accuracy? In this paper we analyze the uncertainty in moraine ages caused by erosion of the moraines, using numerical simulations of moraine surfaces and their changes over time. We do not consider random analytic errors (sample preparation, accelerator mass spectrometric measurements) or systematic errors (radionuclide half life, production rate, temporal variation, stable element measurements, carrier and standards, fractionation, spectrometry, assigned constants) that have been reported in the range of 8 and $10 \%$ respectively of the boulder age (Gosse and Phillips, 2001) or more

\footnotetext{
* Corresponding author.

E-mail address: putkonen@u.washington.edu (J. Putkonen).

Supplementary data for this article (Appendix) are available on Science Direct (http://www.sciencedirect.com).
}

recently $3-5 \%$ of the boulder age (J.O. Stone, pers. comm., 2002). For the purpose of our analysis we assume that the published boulder ages are true and accurate, and that moraine formation is instantaneous. In reality it may take centuries to millennia to form the moraine (Gosse et al., 1995b).

Here we analyze all existing cosmogenic exposure ages for boulders from moraines and show that most published data sets show significant scatter in ages, which can best be explained by erosion of the moraine matrix. We model the moraine topographic evolution and show that the geological uncertainty in moraine ages depends on the initial moraine size and age, in such a way that older and taller moraines are associated with the larger errors. We give guidelines for sample size (number of boulders), which can also be used to assess the potential geological age uncertainty related to reported moraine ages.

Proper interpretation of cosmogenic exposure ages of eroding moraines requires understanding three sets of processes: (1) erosion of the sampled boulders, which reduces cosmogenic isotope concentrations (Gillespie and Bierman, 1995; Nishiizumi et al., 1989; Phillips et al., 1997); (2) the processes that deliver preexposed boulders to moraines, 
and; (3) erosion of the moraine and exhumation of previously shielded boulders. Our current model follows the concept described in Hallet and Putkonen (1994).

When using cosmogenic exposure ages of boulders to date the moraines themselves, the duration of exposure of boulders is generally assumed to be the same as the age of the moraine. However, in reality, no simple relation exists between the age of a moraine and the exposure age of boulders exposed on its surface. Following glacier retreat, most boulders initially lying on the moraine surface tend to retain their position (otherwise the crests would be devoid of boulders, which is not the case); however, over time additional boulders emerge at the surface, as the finegrained matrix is transferred downslope by wind, water and creep. These boulders, which were partially or completely shielded from cosmic radiation during the early history of the moraine, will have exposure ages that are less than the age of moraine itself. Thus, the exposure age of surface boulders on a moraine crest is not only a function of moraine age, but also of moraine erosion history. Boulder weathering rates are poorly known, but qualitative indicators (boulder counts) suggest that over time the oldest and weakest boulders completely disintegrate, further skewing the boulder age distribution (Colman and Pierce, 1986; Sharp and Birman, 1963). To the extent that boulders themselves erode, they should have younger exposure ages than the age of the moraine on which they were found, due to the removal of the surface layer that was enriched with cosmogenic isotopes. An unknown amount of boulder erosion increases the uncertainty of the moraine age and therefore hinders reliable correlation of moraines from different field areas with different erosion rates. Moreover, when boulder erosion is rapid enough to disintegrate the oldest boulders, the fundamental relation between boulder and moraine age is disrupted, and nested moraines may even exhibit apparent age reversals due to intricate interplay among subsurface and subaerial boulder erosion rates and moraine matrix erosion (Hallet and Putkonen, 1994). Because of the potential complications related to boulder attrition and complete disintegration of the boulders on very old moraines, we limit our modeling exercise to moraines that are younger than $100,000 \mathrm{yr}$.

We have analyzed all published cosmogenic dates of boulders from moraines that we have been able to find in our literature search (Table 1). Our analysis shows that large age variation is characteristic of almost all of these data sets; moreover, this result can be explained by geomorphic processes acting on these moraines. We demonstrate that the number of boulders with prior exposure is small, but it varies from site to site, presumably due to the local climate and lithology. Therefore our analysis strictly reflects only geographic areas and climates listed in Table 1. We apply our theoretical model to explore the effect of sample number (of boulders) on the dating accuracy [i.e., the difference in age between the oldest dated boulder (excluding boulders with prior exposure) and the moraine age]. Finally, we show
Table 1

All publications of moraine ages that are based on exposure ages of surface boulders and the corresponding field area

\begin{tabular}{ll}
\hline Reference & Field area \\
\hline Barrows et al. (2002) & Snowy Mts. Tasmania, Australia \\
Briner et al. (2001) & Ahklun Mountains, Alaska, USA \\
Brook et al. (1993) & Arena Valley, Antarctica \\
Brook et al. (1995) & McMurdo Sound, Antarctica \\
Davis et al. (1999) & Crater Lake, Baffin Island, Canada \\
Duk-Rodkin et al. (1995) & MacKenzie Mts, NW Terr. Canada \\
Gosse et al. (1995a) & Wind River Range, Wyoming, USA \\
Gosse et al. (1995b) & Wind River Range, Wyoming, USA \\
Gualtieri et al. (2000) & Koryak Mts, far eastern Russia \\
Ivy-Ochs et al. (1999) & European Alps, Switzerland \\
& Arthurs pass, New Zealand \\
Licciardi et al. (2001) & Yellowstone, Montana, USA \\
Marsella et al. (2000) & Pangnirtung Fj. Baffin Is. Canada \\
Owen et al. (2001) & Lahul Himalaya, India \\
Owen et al. (2002) & Karakoram Mts, Pakistan \\
Phillips et al. (1990) & Sierra Nevada, California, USA \\
Phillips et al. (1996) & Sierra Nevada, California, USA \\
Phillips et al. (1997) & Wind River Range, Wyoming, USA \\
Shanahan and Zreda (2000) & Equatorial East Africa \\
Steig et al. (1998) & Baffin Island, Canada \\
Swanson and Porter (2000) & Cascades, Washington, USA \\
Zreda and Phillips (1995) & Wind River Range, Wyoming, USA \\
& Eastern Sierra Nevada, California, USA \\
Zreda et al. (1994) & Eastern Sierra Nevada, California, USA \\
\hline
\end{tabular}

the relation between moraine age, initial moraine height, and number of boulders required to sample for $10 \%$ dating accuracy (95\% probability).

\section{Methods}

The degradation model that tracks the evolution of moraine form and boulder exhumation was introduced by Hallet and Putkonen (1994). The moraine is assumed to have an initial triangular cross section with both sides at angle of repose $\left(34^{\circ}\right)$. This initial condition seems reasonable in view of the sharp-crested form typical of moraines that are recently exposed by glacier retreat. However, moraines quickly relax from a sharp-crested form, and hence this assumption has little influence on long-term topographic evolution. In cases where the initial moraine slopes are gentler than the angle of repose, our sampling protocol would give the limiting lower estimate of the dating accuracy.

For this project the degradation model was improved to account for a minimum boulder height above the moraine surface to avoid small boulders, which is the common practice when boulders are sampled in the field. It was also improved to account for subsurface spallogenesis and also for production of ${ }^{36} \mathrm{Cl}$ by the capture of thermal neutrons.

In the model the moraine flattens and widens with time as fine-grained sediment is transferred downslope from the moraine crest, exposing previously buried boulders there. 
The conservation of sediment leads to an expression relating the rate of change of the local surface elevation, $d z / d t$, to the divergence of sediment flux, $q$ :

$$
d z / d t=-d q / d x
$$

where $x$ is the horizontal distance in a plane perpendicular to the moraine axis. This relation is applicable for any diffusive sediment-transport process and for motion restricted down the fall line (the path that follows the steepest local slope), which in the case of moraines, can be adequately modeled by considering downslope sediment transfer perpendicular to the moraine axis.

We recognize that the rate of moraine degradation depends on several processes that are not well defined. Therefore, for this theoretical analysis, we are guided by empirical survey data collected from moraines in the eastern Sierra Nevada at Bloody Canyon (Burke and Birkeland, 1979; Phillips et al., 1990; Sharp and Birman, 1963). These moraines are well studied and representative of moraines typically formed by alpine glaciers.

Denudation rates of slopes have been studied on erosional scarps (Andrews and Bucknam, 1987; Andrews and Hanks, 1985; Hanks and Andrews, 1989; Hanks et al., 1984; Pierce and Colman, 1986), degraded normal faults (Nash, 1980a, b), moraines (Bursik, 1991; Hallet and Putkonen, 1994; Phillips et al., 2000). In such studies the degradation of small escarpments up to about $10 \mathrm{~m}$ high was viewed as resulting dominantly from progressive and intermittent downslope sediment motion, known as soil creep.

The topographic diffusivity, $\kappa$, represents the volume of sediment moving down sloper per unit time and per unit length transverse to the slope divided by the slope inclination, $d z / d x$. The simplest relation expressing the general increase in soil flux with slope steepness is:

$$
q=-\kappa d z / d x .
$$

For short slopes, $\kappa$ typically ranges between $10^{-2}$ and $10^{-4}$ $\mathrm{m}^{2} \mathrm{yr}^{-1}$ over a wide spectrum of geographic areas, climates and alluvial substrates (Hanks et al., 1984). For longer slopes, as high as $20 \mathrm{~m}$ on erosional scarps in alluvium, $\kappa$ increases linearly with distance downslope (Pierce and Colman, 1986), presumably because of the increasing importance of slope-length dependent sediment transport by sheet-wash and rilling.

To treat the evolution of moraines ranging in height from tens to hundreds of meters, we assume that topographic diffusivity takes the form $\kappa=\alpha+\beta x$, where $\alpha\left(\mathrm{m}^{2} \mathrm{yr}^{-1}\right)$ and $\beta\left(\mathrm{m} \mathrm{yr}^{-1}\right)$ are site-specific constants. The transport equation relating soil flux to slope, together with the expressions for the conservation of material and for $\kappa$, lead to a generalized diffusion equation for topographic evolution:

$$
\frac{\partial z}{\partial t}=\frac{\partial}{\partial x}\left(\kappa \frac{\partial z}{\partial x}\right)=\kappa \frac{\partial^{2} z}{\partial x^{2}}+\beta \frac{\partial z}{\partial x} .
$$

With proper boundary conditions this equation can readily

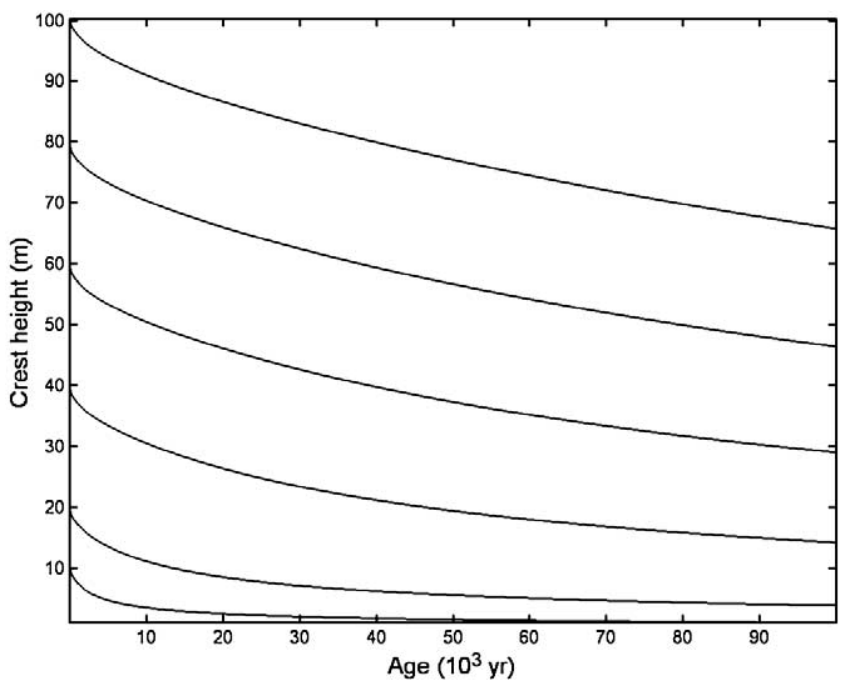

Fig. 1. Moraine crest lowering through time for six moraines of different initial height: $100-10 \mathrm{~m}$. Topographic diffusivity (i.e., soil erosion rate) is based on actual survey results of moraines measured in Bloody Canyon, Sierra Nevada. Note that for small moraines (initial height $<20 \mathrm{~m}$ ) the early $(0-5,000 \mathrm{yr})$ crest lowering is relatively large followed by a long time period of relatively little crest lowering. Consequently, most boulders will be exhumed within the first few thousands of years after the moraine formation, and most surface boulders on old ( $>30,000 \mathrm{yr}$ ) moraines would record an exposure age relatively close to the moraine formation age. This is also reflected in Table 2, which shows that old and small ( $\geq 80,000 \mathrm{yr}$, $\leq 20 \mathrm{~m}$ initial height) moraines require sampling one to three boulders to determine a boulder age that is $\geq 90 \%$ moraine age.

be solved numerically with a finite-difference approximation. The part of the model presented above yields topographic evolution through time, including the surface-lowering rate at the moraine crest (Fig. 1), which permits determination of the rate at which new boulders emerge at the moraine surface as they are exposed.

We estimated the total number of boulders with prior exposure using the boulder-exhumation model, and an additional module to account for the prior exposure. We assume that the boulders with varying prior exposure are delivered randomly to the valley bottom, and mixed with fresh rock material that is eroded by the advancing glacier. The prior exposure varies between zero and a maximum age that is constrained by the statistical properties described below. In the model, three separate stages determine the apparent cosmogenic age of the surface boulder: (1) the length of prior exposure before the boulder was incorporated into the moraine matrix, (2) length of the burial and related decay of cosmogenically derived isotopes, and (3) length of "reexposure" at the surface. For example, the half-life for ${ }^{36} \mathrm{Cl}$ is $301,000 \mathrm{yr}$, and the corresponding decay constant is $2.303 \times 10^{-6} \mathrm{yr}^{-1}$ (Lederer and Shirely, 1978). A typical maximum burial time of $100,000 \mathrm{yr}$ would result in a decay of $20 \%$ of the accumulated ${ }^{36} \mathrm{Cl}$, and hence the apparent cosmogenic age would be $80 \%$ of the prior exposure age even if the boulder was never exposed on the moraine surface. 


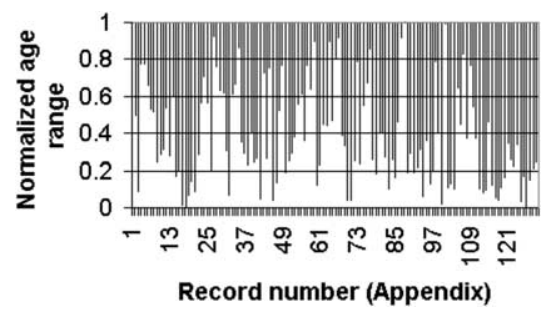

Fig. 2. Normalized boulder age range for each dated moraine surface (Appendix). The boulder ages are normalized to the oldest age in each group and the range between the oldest and youngest ages are shown. A small age range (a bar $<0.1$ in length) is shown by a short column and means that all boulders record an age that is very close to the moraine age (tight age cluster). A large age range (a bar $>0.8$ in length) means that the set of boulders contains both old and very recently exposed boulders and is shown by a long bar. The average age range for all moraine surfaces $(0.38)$ is the mean of the all normalized age ranges. This shows that tight age clusters are rare and that a considerable scatter in boulder ages from each respective moraine is common.

In our compilation, we followed the original author's suggested data interpretation to omit the older outliers, which decreased the individual age ranges. However, younger outliers were included in our data compilation, because their presence is predicted by the moraine degradation model and bear on the core of this paper. The normalized age range is calculated by dividing (normalizing) the maximum and minimum boulder ages in a set from a single moraine by the maximum boulder age. The difference between these numbers is the normalized age range (values between 0 and 1 ). The age ranges are reported without older outliers in Fig. 2.

For example, a set of boulders is dated from a single moraine and the oldest age in the set is 50,000 $\mathrm{yr}$ and the youngest is $10,000 \mathrm{yr}$. The normalized age for the oldest boulder (50,000 yr) is 1 and for youngest boulder $(10,000$ yr) it is 0.2 , and it follows that the normalized boulder age variation is $(1-0.2=) 0.8$. In the figure the age range is shown by the vertical span of each individual bar. Every column begins at 1 , the normalized age of the oldest boulder.

\section{Results}

Our moraine degradation model predicts the transverse topographic profiles of moraines in excellent agreement with observed forms (Hallet and Putkonen, 1994). After a given time, the moraine profile is a function only of its initial configuration and transport parameters. Thus, the present form of a moraine of known age can be used to evaluate the time-averaged transport parameters for the representative field site at Bloody Canyon. A close match between computed and surveyed profiles requires the rate constants of the spatially varying topographic diffusivity $\kappa$ to be $\alpha=1.2 \times 10^{-2} \mathrm{~m}^{2} \mathrm{yr}^{-1}$ and $\beta=1.6 \times 10^{-4} \mathrm{~m} \mathrm{yr}^{-1}$. Sums of least-square differences were used to determine the best value of $\alpha$ and $\beta$, with a resolution of approximately $20 \%$. Near the crest, $\kappa$ approaches $\alpha$ and is comparable with the larger values obtained for $\sim 10$-m fault scarps in the Great Basin (Hanks et al., 1984).

\section{Boulder age range}

The cosmogenic exposure ages from moraines (Appendix) show that boulder age ranges (difference between oldest and youngest boulder age from one moraine) on temporally uniform surfaces commonly exceeded the estimated random and systematic errors $(12 \%)$. The mean range of all series is 0.38 ( $38 \%$ of the maximum age). Large age ranges are common to most of the published data sets.

\section{Prior exposure of boulders}

Of all 638 dated boulders included in this analysis, 13 (2.0\%) had exposure prior to deposition in the moraine, according to the authors of the original reports (this percentage is a maximum estimate because the boulder count is not reported in all published studies). The published data sets indicate that boulders with prior exposure are rarely identified, but those that are identified are on average 2.0 times older than the oldest boulder in the remaining set.

The model was run for typical cases of 20,000- and 100,000-yr-old moraines and the maximum prior exposure and total percentage of boulders with prior exposure were allowed to vary until the statistical targets were achieved (2.0\% boulders older than the formation, mean age of boulders that are older than the formation is 2.0 times the moraine age, these values are based on the observations Appendix). We found that $2.4 \%$ of the moraine boulders have prior exposure, but only $2.0 \%$ are older than the formation. The maximum prior exposure is about $250 \%$ of the formation age. This analysis suggests that about $15 \%$ of the boulders carrying prior exposure are not identified as such, because their combined predepositional and postdepositional exposure is less than the age of the moraine.

\section{Dating accuracy}

The moraine-degradation model was run for representative parameter values $\left(\alpha=1 \times 10^{-2} \mathrm{~m}^{2} \mathrm{yr}^{-1}, \beta=1 \times\right.$ $10^{-4} \mathrm{~m} \mathrm{yr}^{-1}$ ), and 5000 sets of 15 boulders were sampled on the moraine crest to calculate boulder age averages and standard deviations for moraines of various initial heights $(10-100 \mathrm{~m})$ and ages $(20,000-100,000 \mathrm{yr})$. Table 2 shows the number of boulders that must be sampled in order to find one boulder whose exposure age is $\geq 90 \%$ of the moraine age (95\% confidence), as a function of initial moraine height and moraine age. Table 2 indicates that to date small moraines, significantly fewer randomly chosen boulders need to be sampled from the crest than to date large and old moraines.

We tested the sensitivity of the maximum age (for a set 
Table 2

The number of boulders (diameter $>1 \mathrm{~m}$ ) that need to be randomly sampled from a moraine crest to find a boulder whose age is $\geq 90 \%$ of the moraine age with $95 \%$ probability, for a given initial moraine height and age, to determine an approximate initial height for a moraine of a given age consult (Fig. 1)

\begin{tabular}{|c|c|c|c|c|c|c|c|c|c|c|}
\hline \multirow[t]{2}{*}{ Moraine age $\left(10^{3} \mathrm{yr}\right)$} & \multicolumn{10}{|c|}{ Initial moraine height $(\mathrm{m})$} \\
\hline & 100 & 90 & 80 & 70 & 60 & 50 & 40 & 30 & 20 & 10 \\
\hline 100 & 7 & 7 & 7 & 7 & 7 & 6 & 5 & 5 & 3 & 1 \\
\hline 80 & 7 & 7 & 7 & 7 & 7 & 7 & 6 & 5 & 3 & 2 \\
\hline 60 & 7 & 7 & 7 & 7 & 7 & 6 & 6 & 5 & 4 & 2 \\
\hline 40 & 6 & 6 & 6 & 6 & 6 & 6 & 6 & 5 & 4 & 2 \\
\hline 20 & 5 & 5 & 5 & 5 & 5 & 5 & 5 & 5 & 4 & 3 \\
\hline
\end{tabular}

of seven boulders from a 100,000-year-old moraine initially $60 \mathrm{~m}$ high) over a broad range of diffusion parameters $(\alpha=$ $1 \times 10^{-3}-1 \times 10^{-1} \mathrm{~m}^{2} \mathrm{yr}^{-1}, \beta=1 \times 10^{-5}-1 \times 10^{-3}$ $\mathrm{m} \mathrm{yr}^{-1}$ ) and determined that any combination of $\alpha$ and $\beta$ yields an average maximum age within $8 \%$ of the reference maximum boulder age (Fig. 3).

\section{Discussion}

In the computer model the boulders are chosen randomly from the crest of the moraine. It has been suggested that careful consideration of boulder characteristics allows the researcher to find the oldest boulders on the moraine, improving the moraine dating accuracy substantially. However, it has never been proven that one could successfully choose the oldest surface boulders by their appearance.

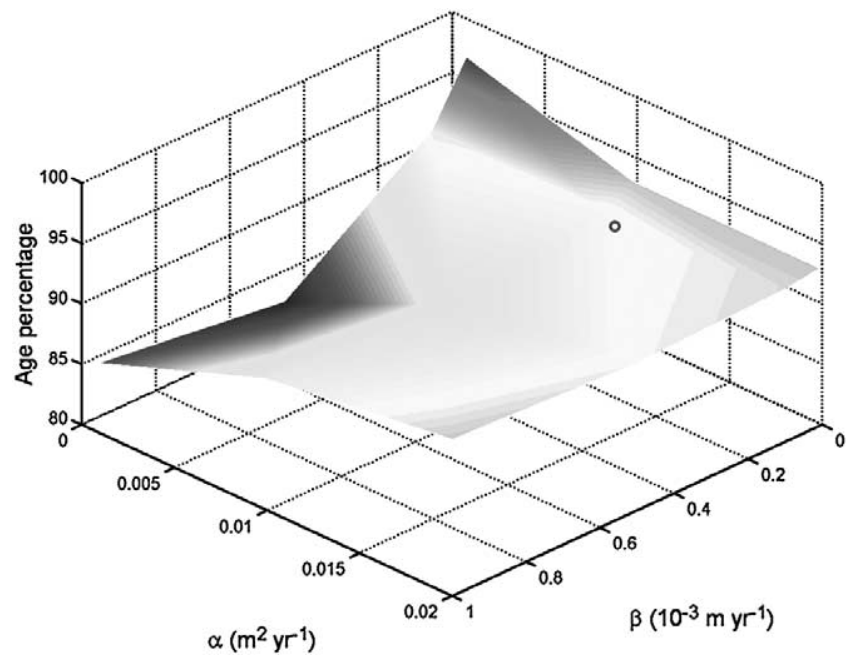

Fig. 3. Modeled sensitivity of average maximum boulder age to topographic diffusion parameters ( $\alpha$ and $\beta$ ), which collectively represent the rate of soil erosion processes (sheet wash, rilling, soil splash, burrowing animals, vegetation, etc.). The sensitivity of the maximum age (for a set of seven boulders) over a broad range of diffusion parameters $\left(\alpha=1 \times 10^{-1}\right.$ $-1 \times 10^{-1} \mathrm{~m}^{2} \mathrm{yr}^{-1}, \beta=1 \times 10^{-5}-1 \times 10^{-3} \mathrm{~m} \mathrm{yr}^{-1}$ ) was tested and determined that any combination of $\alpha$ and $\beta$ yields an average maximum age within $8 \%$ of our sample case (initial moraine height $60 \mathrm{~m}$, age 100,000 $\mathrm{yr}$ ). The white circle marks the combination of diffusion parameters that was determined for Bloody Canyon moraines.
Moreover, if this were the case, we would not see the large age ranges shown by most of the published data (Appendix, available on Science Direct (http://www.sciencedirect.com); Fig. 2). It is also conceivable that one can introduce unwanted bias in the boulder ages by subjectively choosing the boulders, based on varying criteria (see Appendix, for boulder sampling criteria). Annual freeze-thaw cycle and related rock upheaval may explain part of the observed age range in Arctic and alpine settings.

The observed tight age clusters for young, small moraines ( $\sim 20,000 \mathrm{yr})$ reported by Gosse et al. (1995a, 1995b) confirm our model results. Relatively little surface lowering has occurred, and hence majority of the boulders record an age that is close to the moraine age. Based on published field data (Table 1) and our degradation model, it appears that small moraines $(<20 \mathrm{~m}$ initial height) have generally degraded little and therefore the exhumation of fresh boulders is a less of a complication for cosmogenic exposure dating of small moraines. However, for old and tall moraines $(>40,000 \mathrm{yr},>50 \mathrm{~m})$ the moraine degradation becomes a serious problem and requires more boulders to be sampled for equal dating accuracy.

The small percentage of boulders with prior exposure may be explained by various hypotheses: (1) glacial landscapes are in disequilibrium, and are preferentially eroded at the base of the glaciers (instead of shallow rockfalls on the side of the valleys); (2) rockfalls at the valley walls are seated deep enough $(>2 \mathrm{~m})$ to dislodge predominantly fresh rock that has been shielded from the cosmic-ray flux, and thus only one of the six rectangular sides of these boulders carry prior exposure; (3) rate of valley-wall denudation and subsequent burial of eroded rock at the valley floor is rapid enough to make the debris indistinguishable by age from freshly eroded glacial boulders; (4) weathered rock-fall debris breaks down rapidly to clasts smaller than the sampled boulders, or is transported fluvially beyond the end moraines; (5) most of the debris with prior exposure is preferentially deposited near the base of the moraine during initial advance of the glacier and thus is usually not exposed for sampling of surface boulders for cosmogenic nuclide analysis; (6) not all statistical outliers were reported by researchers. It is plausible that a combination of the above factors 
contributes to the low percentage of boulders with prior exposure.

Our analyses of published cosmogenic exposure ages obtained for moraine boulders indicate that surface lowering of moraines and related boulder age range are characteristic and can be disregarded only under special circumstances: (1) when young moraines are sampled and there has not been sufficient time to expose fresh boulders (Fig. 1); (2) when small moraines are sampled and surface lowering is less than the diameter of the smallest sampled boulder; (3) when sampled moraines have low denudation rates, e.g., moraines in the McMurdo Dry Valleys, Antarctica; and (4) when sampling wide-crested composite moraines where the moraine surface has remained level over time and, hence, the surface degradation rate is small.

Our results further indicate that for accurate dating of moraines it is desirable to sample large boulders that are completely exhumed and to select the smallest moraines that have undergone minimal crest lowering. The greater the size of the exposed surface boulder, the longer it has likely to have been exposed to cosmic rays. However, the largest boulders (diameter $>10 \mathrm{~m}$ ) may also be rockfall deposits rather than products of basal erosion of the ice. These are likely to have been exposed in their original locations in the valley wall, and are unlikely to have been buried in the valley bottom.

The total crest lowering of the moraine is a function of initial moraine height, age of moraine and topographic diffusivity. If all other environmental variables are held constant, the rate at which moraine crests lower decreases with the moraine size. Climatic variables are also important, as topographic diffusivity $(\kappa)$, is a function of rainfall amount, rainfall rate, vegetation cover, soil infiltration capacity, and soil grain-size distribution (Dunne and Leopold, 1995, pages 510-522; Selby, 1990, pages 94-112). Topographic diffusivity is generally not well known and should be defined for the specific climatic and geographic region of interest.

The above analysis of preexposed boulder ages to model landscape evolution should highlight the importance of publishing all cosmogenic exposure data, even if it does not seem to serve the direct purpose of moraine dating. In reality, some data may never get published because of the large age ranges, and thus the problem may be even larger than perceived.

\section{Conclusions}

Our analyses of all published cosmogenic exposure ages obtained for moraine boulders indicate that surface lowering of moraines and related boulder age variation is characteristic of most published data sets and can be disregarded only under special circumstances. Based on our model and analyses for accurate dating of moraines it is desirable to sample randomly, large boulders (1-5 m diameter), and to select the smallest moraines that have undergone minimal crest lowering.

Our moraine degradation model suggests that by sampling completely exhumed boulders randomly on the crest of a moraine and by following sampling guidelines given in Table 2, the greatest boulder age (after removing preexposed boulders) will generally be $\geq 90 \%$ of the moraine age (95\% probability). The greatest boulder age, rather than the average age, best represents the age of the moraine. Our findings also demonstrate that the model results are only weakly sensitive to a broad range of topographic diffusion parameters $(\kappa)$ that collectively represents soil erosion processes (sheet-wash, rilling, soil splash, burrowing animals, vegetation, etc.).

About $2 \%$ of all reported moraine boulders have prior exposure. This low percentage suggests a landscape disequilibrium, inhomogeneous exposure or nonrepresentative sampling of preexposed boulders for cosmogenic nuclide analysis.

\section{Acknowledgments}

The authors express gratitude to colleagues at Quaternary Research Center and University of Washington Department of Earth and Space Sciences: B. Hallet, A. Gillespie, and S. Porter, who reviewed earlier versions of this manuscript and gave valuable comments. The insightful suggestions from reviewers J.O. Stone and P.T. Davis and anonymous reviewers are greatly appreciated.

\section{References}

Andrews, D.J., Bucknam, R.C., 1987. Fitting degradation of shoreline scarps by a non-linear diffusion model. Journal of Geophysical Research 92

Andrews, D.J., Hanks, T.C., 1985. Scarp degraded by linear diffusion: inverse solution for age. Journal of Geophysical Research 90, 1019310208.

Barrows, T.T., Stone, J.O., Fifield, L.K., Cresswell, R.G., 2002. The timing of the last Glacial Maximum in Australia. Quaternary Science Reviews 21, 159-173.

Briner, J.P., Swanson, T.W., Caffee, M., 2001. Late Pleistocene cosmogenic $36 \mathrm{Cl}$ glacial chronology of the southwestern Ahklun Mountains, Alaska. Quaternary Research 56, 148-154.

Brook, E.J., Kurz, M.D., Ackert, J.R.P., Denton, G.H., Brown, E.T., Raisbeck, G.M., Yiou, F., 1993. Chronology of Taylor Glacier advances in Arena Valley, Antarctica, using in situ cosmogenic ${ }^{3} \mathrm{He}$ and ${ }^{10} \mathrm{Be}$. Quaternary Research 39, 11-23.

Brook, E.J., Kurz, M.D., Ackert, J.R.P., Raisbeck, G.M., Yiou, F., 1995. Cosmogenic nuclide exposure ages and glacial history of Late Quaternary Ross Sea Drift in McMurdo Sound, Antarctica. Earth and Planetary Science Letters 131, 41-56.

Burke, R.M., Birkeland, P.W., 1979. Reevaluation of multiparameter relative dating techniques and their application to the glacial sequence along the eastern escarpment of the Sierra Nevada, California. Quaternary Research 11, 21-51.

Bursik, M., 1991. Relative dating of moraines based on landform degradation, Lee Vining Canyon, California. Quaternary Research 35, 451455 . 
Colman, S.M., Pierce, K.L., 1986. Glacial sequence Near McCall, Idaho: weathering rinds, soil development, morphology and other relative age criteria. Quaternary Research 25, 25-42.

Davis, P.T., Bierman, P.R., Marsella, K.A., Caffee, M.W., Southon, J.R., 1999. Cosmogenic analysis of glacial terrains in the eastern Canadian Arctic: a test for inherited nuclides and the effectiveness of glacial erosion. Annals of Glaciology 28, 181-188.

Duk-Rodkin, A., Barendregt, R.W., Tarnocai, C., Phillips, F.M., 1995. Late Tertiary to Late Quaternary record in the MacKenzie Mountains, Northwest Territories, Canada: stratigraphy, paleosols, paleomagnetism, and Chlorine-36. Canadian Journal of Earth Sciences 33, 875895.

Dunne, T., Leopold, L.B., 1995. Water in Environmental Planning. W.H. Freeman and Company, New York.

Gillespie, A.R., Bierman, P.R., 1995. Precision of terrestrial exposure ages and erosion rates estimated from analysis of cosmogenic isotopes produced in situ. Journal of Geophysical Research 100 B12, 24,63724,649

Gosse, J.C., Evenson, E.B., Klein, J., Lawn, B., Middleton, R., 1995a Precise cosmogenic ${ }^{10} \mathrm{Be}$ measurements in Western North America: support for global Younger Dryas cooling event. Geology 23, 877880.

Gosse, J.C., Klein, J., Evenson, E.B., Lawn, B., Middleton, R., 1995b. Beryllium-10 dating of the duration and retreat of the last Pinedale glacial sequence. Science 268, 1329-1333.

Gosse, J.C., Phillips, F.M., 2001. Terrestrial in situ cosmogenic nuclides: theory and application. Quaternary Science Reviews 20, 1475-1560.

Gualtieri, L., Glushkova, O., Brigham-Grette, J., 2000. Evidence for restricted ice extent during the last glacial maximum in the Koryak Mountains of Chukotka, far eastern Russia. GSA Bulletin 112, 11061118

Hallet, B., Putkonen, J.K., 1994. Surface dating of dynamic landforms: young boulders on aging moraines. Science 265, 937-940.

Hanks, T.C., Andrews, D.J., 1989. Effect of far-field slope on morphological dating of scraplike landforms. Journal of Geophysical Research 94, 565-573.

Hanks, T.C., Bucknam, R.C., Lajoie, K.R., Wallace, R.E., 1984. Modification of wave-cut and faulting-controlled landforms. Journal of Geophysical Research 89, 5771.

Ivy-Ochs, S., Schluchter, C., Kubik, P., Denton, G.H., 1999. Moraine exposure dates imply synchronous Younger Dryas glacier advances in the European Alps and in the Southern Alps of New Zealand Geografiska Annaler 81, 313-323.

Lederer, C.M., Shirely, V.S., 1978. Table of Isotopes. Wiley, New York.

Licciardi, J.M., Clark, P.U., Brook, E.J., Pierce, K.L., Kurz, M.D., Elmore, D., Sharma, P., 2001. Cosmogenic ${ }^{3} \mathrm{He}$ and ${ }^{10} \mathrm{Be}$ chronologies of the late Pinedale northern Yellowstone ice cap, Montana, USA. Geology 29, 1095-1098.

Marsella, K.A., Bierman, P.R., Davis, P.T., Caffee, M.W., 2000. Cosmogenic ${ }^{10} \mathrm{Be}$ and ${ }^{26} \mathrm{Al}$ ages for the Last Glacial Maximum, eastern Baffin Island, Arctic Canada. GSA Bulletin 112, 1296-1312.

Nash, D.B., 1980a. Forms of bluffs degraded for different lengths of time in Emmet County, Michigan, USA. Earth Surface Processes 5, 331345.
Nash, D.B., 1980b. Morphologic dating of degraded normal fault scarps. Journal of Geology 88, 353-360.

Nishiizumi, K., Winterer, E.L., Kohl, C.P., Klein, J., Middleton, R., Lal, D., Arnold, J.R., 1989. Cosmic ray production rates of ${ }^{10} \mathrm{Be}$ and ${ }^{26} \mathrm{Al}$ in Quartz from glacially polished rocks. Journal of Geophysical Research 94, 17907-17915.

Owen, L.A., Finkel, R.C., Caffee, M.W., Gualtieri, L., 2002. Timing of multiple late Quaternary glaciations in the Hunza Valley, Karakoram Mountains, northern Pakistan: defined by cosmogenic radionuclide dating of moraines. GSA Bulletin 114, 593-604.

Owen, L.A., Gualtieri, L., Finkel, R.C., Caffee, M.W., Benn, D.I., Sharma, M.C., 2001. Cosmogenic radionuclide dating of glacial landforms in the Lahul Himalaya, northern India: defining the timing of late Quaternary glaciation. Journal of Quaternary Science 16, 555-563.

Phillips, F.M., Zreda, M., Shanahan, T.M., Bursik, M.I., and Plummer, M.A. (2000). Cosmogenic depth profiles and erosion modeling: new results from Bloody Canyon moraines, Mono Basin, California, in: American Geophysical Union Fall Meeting, AGU, San Francisco, USA.

Phillips, F.M., Zreda, M.G., Benson, L.V., Plummer, M.A., Elmore, D., Sharma, P., 1996. Chronology for fluctuations in Late Pleistocene Sierra Nevada glaciers and lakes. Science 274, 749-751.

Phillips, F.M., Zreda, M.G., Gosse, J.C., Klein, J., Evenson, E.B., Hall, R.D., Chadwick, O.A., Sharma, P., 1997. Cosmogenic ${ }^{36} \mathrm{Cl}$ and ${ }^{10} \mathrm{Be}$ ages of Quaternary glacial and fluvial deposits of the Wind River Range, Wyoming. GSA Bulletin 109, 1453-1463.

Phillips, F.M., Zreda, M.G., Smith, S.S., Elmore, D., Kubik, P.W., Sharma, P., 1990. Cosmogenic Chlorine-36 Chronology for glacial deposits at Bloody Canyon, eastern Sierra Nevada. Science 248, 1529-1532.

Pierce, K.L., Colman, S.M., 1986. Effect of height and orientation (Microclimate) on geomorphic degradation rates and processes, Late-Glacial terrace scarps in Central Idaho. Geological Society of America Bulletin 97, 869.

Selby, M.J., 1990. Hillslope Material \& Processes. Oxford University Press.

Shanahan, T.M., Zreda, M., 2000. Chronology of Quaternary glaciations in East Africa. Earth and Planetary Science Letters 177, 23-42.

Sharp, R.P., Birman, J.H., 1963. Additions to classical sequence of Pleistocene glaciations, Sierra Nevada, California. Geological Society of America Bulletin 74, 1079-1086.

Steig, E.J., Wolfe, A.P., Miller, G.H., 1998. Wisconsinan refugia and the glacial history of eastern Baffin Island, Arctic Canada: coupled evidence from cosmogenic isotopes and lake sediments. Geology 26, 835-838.

Swanson, T.W., and Porter, S.C. (2000). ${ }^{36} \mathrm{Cl}$ evidence for maximum late Pleistocene glacier extent in the Cascade Range during Marine Isotope Substage 5d, in: Geological Society of America Abstracts with Programs, Geological Society of America, Reno, Nevada, pp. A-511.

Zreda, M.G., Phillips, F.M., 1995. Insights in the alpine moraine development from cosmogenic ${ }^{36} \mathrm{Cl}$ buildup dating. Geomorphology 14, 149 156.

Zreda, M.G., Phillips, F.M., Elmore, D., 1994. Cosmogenic ${ }^{36} \mathrm{Cl}$ accumulation in unstable landforms, 2, Simulations and observations on eroding moraines. Water Resources Research 30, 3127-3136. 